International Journal of Advanced Biological and Biomedical Research

Available online at http:www.ijabbr.com

Volume 8, Issue 2 (2020) pp. 100-111

DOI: 10.33945/SAMI/IJABBR.2020.2.1

Review Article

\title{
Histamine and Food Allergy
}

\section{Negar Dinarvand, Reza Azizi*}

Department of Biochemistry, School of Pharmacy, Isfahan University of Medical Sciences, Isfahan, Iran

*Corresponding Author E-mail: Azizirr@yahoo.com

Received: 30 June 2019, Revised: 20 August 2019, Accepted: 12 September 2019

\begin{abstract}
Histamine is synthesized via histidine decarboxylase (HDC) in wide types of immune cells and is involved in abundant physiologic and pathologic processes. Histamine is a mediator released during inflammatory reactions, such as food allergy. Food allergy is immunological reactions to 'fight off' specific allergens within food in susceptible individuals. The aim of this study was investigation of the histamine hemostasis and food allergy to discover the relationship between them. Analysis of data from multiple electronic databases such as Scopus, PubMed, Google Scholar and Science Direct were performed. Various criteria were applied to select the articles for inclusion. Food allergy reaction is divided to 4 types of the immune response. These reactions with different mechanisms cause increased concentrations of histamine. Histamine does can make various actions in different tissues. The correct and timely diagnosis of food allergy can lead to reduction of the chemicals release and inhibit of abnormal reaction of the body. According to some studies, measurement of $\mathrm{N}$-methylhistamine ( $\mathrm{NMH}$ ) as the major metabolite of histamine may help to diagnose patients with food-allergen induced clinical symptoms.
\end{abstract}

Key words: Histamine, Food allergy, Histidine decarboxylase

\section{Introduction}

Histamine (2-[4-imidazolyl]-ethylamine), as an aminergic neurotransmitter, is involved in abundant physiologic and pathologic processes, such as, inflammation, pruritus and vascular leak (De Benedetto et al., 2015; Maintz and Novak, 2007). It is synthesised by histidine decarboxylase (HDC) in wide types of immune cells including mast cells, basophils, enterochromaffin cells, T cells, keratinocytes, enterochromaffin-like (ECL) cell of the stomach and the brain. Histamine affect through binding to its four receptors belonging to the great family of rhodopsin-like G-protein-couples receptors (GPCRs), as H1R- H2R- H3R- and H4R. Inactivation of histamine is performed by two enzymes of oxidative deamination (DAO) and histidine decarboxylase (HDC) that are responsible of degradation of histamine in extracellular and intracellular respectively. Degranulation of mast cell and basophil by several mechanism lead to histamine release. Food allergy is one of these mechanisms (De Benedetto et al., 2015; Maintz and Novak, 2007; Schwelberger, 2004; Leurs et al., 2011). 
Food allergy is happen when the body makes immunological reactions to 'fight off' specific allergens within food in susceptible individuals, and its prevalence is estimated up to $6 \%$ of young children and $3 \%-4 \%$ of adults (Kumar et al., 2012). Allergens are defined as specific components of food or components within food that are recognized by allergen-specific immune cells. Food allergy can be created by different four types of immune reactions that lead to release immune system chemicals (as: histamine, cytokines, etc.), and elicit abnormal response of the body (Kumar et al., 2012, Verhoeckx et al., 2015). The Aim of this study was the investigation of histamine hemostasis, food allergy to discover relationship between them.

\section{Histamine}

Histamine (2-[4-imidazolyl]-ethylamine) is an aminergic neurotransmitter and involved in abundant physiologic and pathologic processes, like pruritus, inflammation, and vascular leak (De Benedetto et al., 2015; Maintz and Novak, 2007). It is discovered in 1910 by Dale and Laidlaw, in 1932 it was recognized that histamine has biological effects in anaphylactic reaction. A few later histamine was separated from lung and liver tissues and named histamine after the Greek verb histos (tissue) (Leurs et al., 2011; Griffiths, 2004).

\section{Synthesis and metabolism}

Mast cells, basophils, and enterochromaffin cells (existent in the gastric mucosa) are widely known as cellular sources of histamine (Maintz and Novak, 2007). However, other cells, such as $\mathrm{T}$ cells and even keratinocytes, have been recognized to produce histamine in answer to stimulation. The enterochromaffin-like (ECL) cell of the stomach and the brain are another main site of histamine storage and release (Maintz and Novak, 2007, Schwelberger, 2004).

The pyridoxal phosphate (vitamin B-6)-containing histidine decarboxylase (HDC) is responsible for histamine synthesis from the amino acid l-histidine (Maintz and Novak, 2007). Histamine can also be made by some fermentative bacteria, such as Lactobacilli in the gut (from l-histidine via HDC). Histamine is either stored or speedily inactivated by its primary degradative enzymes. Histamine can be metabolized in two methodes: via oxidative deamination by DAO (old name: histaminase) or via ring methylation by histamine-N-methyltransferase (HNMT). This metabolization is supposed to depend on the localization of histamine (Maintz and Novak, 2007; Schwelberger, 2004).

The DAO is secreted into the circulation upon stimulation from plasma membraneassociated vesicular structures in epithelial cells that is stored. Therefore, it has been offered that DAO may be responsible for inhibiting extracellular histamine (after consumption of histamine-rich food) after mediators release (Maintz and Novak, 2007). Conversely, HNMT can inactive histamine only in the intracellular space of cells because it is a cytosolic protein. Therefore, the enzymes do not seem to compete for the histamine, though HNMT has a slightly higher affinity for histamine (kM: 6-13 $\mu \mathrm{mol} / \mathrm{L}$ ) than does DAO (kM: $20 \mu \mathrm{mol} / \mathrm{L})$, and they are expressed in some overlapping tissues. Several further enzymes, including monoamine oxidase B (MAO-B) and Aldehyde dehydrogenase (ALDH2), other process the immediate metabolites of histamine for excretion or recycling (De Benedetto et al., 2015; Maintz and Novak, 2007; Gutowska-Owsiak et al., 2014). 
In mammals, HNMT is widely expressed in tissues, but DAO expression is limited to specific tissues; DAO: the greatest activities are displayed for small bowel colon ascendens (Schwelberger, 2004; Verhoeckx et al., 2015; Ho et al., 2014), placenta and kidney (Żukiewicz-Sobczak et al., 2013; Novak et al., 2001). Lower DAO activity has been debited as a potential indicator of intestinal mucosa injury in inflammatory and neoplastic diseases (Bakker et al., 2001; Coruzzi et al., 2012; Parrish et al., 2017), and in patients undergoing chemotherapy. HNMT: the highest expression is in kidney and liver, spleen, colon, spinal cord cells, bronchi, prostate, ovary, and trachea. HNMT is considered as the key enzyme for histamine inactivation in the bronchial epithelium (Maintz and Novak, 2007; Backhaus et al., 2005; Raithel et al., 1999; Schwelberger, 2004).

\section{Release of histamine}

Immunologic is the most important pathophysiologic mechanism of Mast cell and basophil histamine release. These cells contain preformed mediators, including histamine, into cytoplasmic granules. When IgE antibodies attached to their membranes surface are exposed to appropriate antigen, these are sensitized. Upon activation, their mediators are released into the extracellular environment within minutes, via fusing of the granules with the plasma membrane). Released histamine effects on smooth muscle (contraction), nerve endings, endothelial cells and mucus secretion. After $60 \mathrm{sec}$, histamine is degraded by histamine $\mathrm{N}$ Methyltransferase and by diamine oxidase. Because of histamine has short half-life, To search for histamine, it have to measure its metabolites in urine (Stone et al., 2010).

\section{Mechanism of action}

Histamine performs its effects by binding to its four receptors belonging to the large family of rhodopsin-like GPCRs, as H1R, H2R, H3R, and H4R, based on their discovery (Jemima et al., 2014). The biological results of histamine stimulation are defined by the activation of one (or more) of the histamine receptors. Both H1R and H2R are expressed by various cell types, such as epithelial and endothelial cells, dendritic cells, neutrophils and also $\mathrm{T}$ and $\mathrm{B}$ lymphocytes. H3R expression is focused primarily in the central nervous system. H4R is expressed by cell types of derived from bone-marrow, including $\mathrm{T}$ lymphocytes, dendritic cells, mast cells, eosinophils and epithelial cells. Remarkably, it has been demonstrated that Langerhans cells, professional antigen-presenting cells, selectively express H4R but not H1R or H2R (Gutzmer et al., 2011; Bäumer et al., 2008). The histamine-induced signaling cascade is quite complex. It is proved that most of the allergic and inflammatory effects of histamine are mediated by the H1R, a G $\alpha \mathrm{q} / 11$ receptor (Bakker et al., 2001). When histamine binds to H1R induces GDP/GTP exchange on the $G \alpha_{11}$-subunit, upon which the activated $G \alpha_{q / 11} G \beta \gamma$ heterotrimer dissociates into its corresponding $\mathrm{G}_{11}$-subunit and $\mathrm{G} \beta \gamma$ heterodimer, which can both activate cellular effectors. Activated $\mathrm{G} \alpha_{11}\left(\mathrm{GTP}-\mathrm{G} \alpha_{11}\right)$ activates PLC to induce the formation of InsP3 to calcium mobilization and release diacyl glycerol to activate PKC, that activates the NF- $\mathrm{KB} / \mathrm{I}-\kappa \mathrm{B}$ complex and NF- $\mathrm{\kappa B}$ is translocated to the nucleus to induce gene transcription of a wide variety of genes. Also, free $G \beta \gamma$-subunits activate the $\mathrm{NF}-\kappa \mathrm{B} / \mathrm{I}-\kappa \mathrm{B}$ complex to induce gene transcription by the released $\mathrm{NF}-\kappa \mathrm{B}$ via an as-yet- 
unidentified mechanism (Figure 1) (Bakker et al., 2001; Lim et al., 2005; Horr et al., 2006).

A property of the H2R signaling pathway is the formation of cAMP, by Gs, which cause to activation of protein Kinase A. PKA actions to phosphorylate certain proteins, affecting their activity. Also, histamine could also lead to increase in $\mathrm{Ca}^{+2}$ in some cell types suggested either that it was acting on two different subclasses of $\mathrm{H} 2$ receptors, every linked to separate pathways, or that it was stimulating a single class of $\mathrm{H} 2$ receptor linked to both signaling systems(Figure 2) (Del Valle and Gantz, 1997).

The H3 receptor was coupled to the (Gi/o) G-protein, so it leads to several signal transduction pathways including inhibition of cAMP formation.

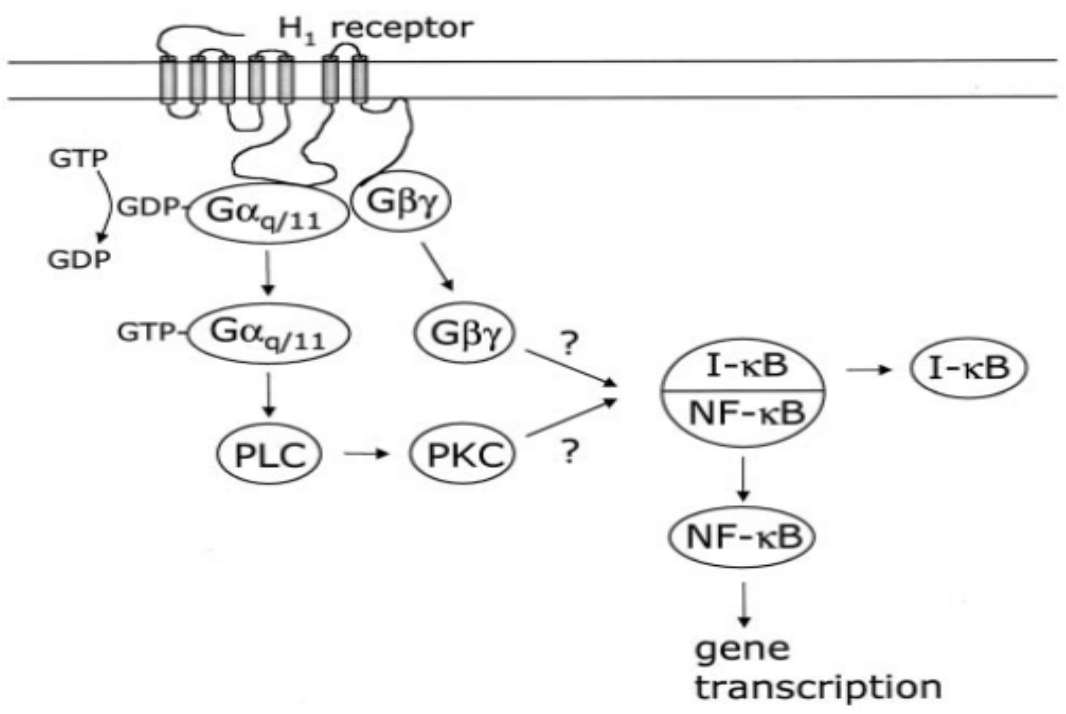

Figure 1. Proposed mechanism of H1 receptor activation [Bakker et al., 2001]
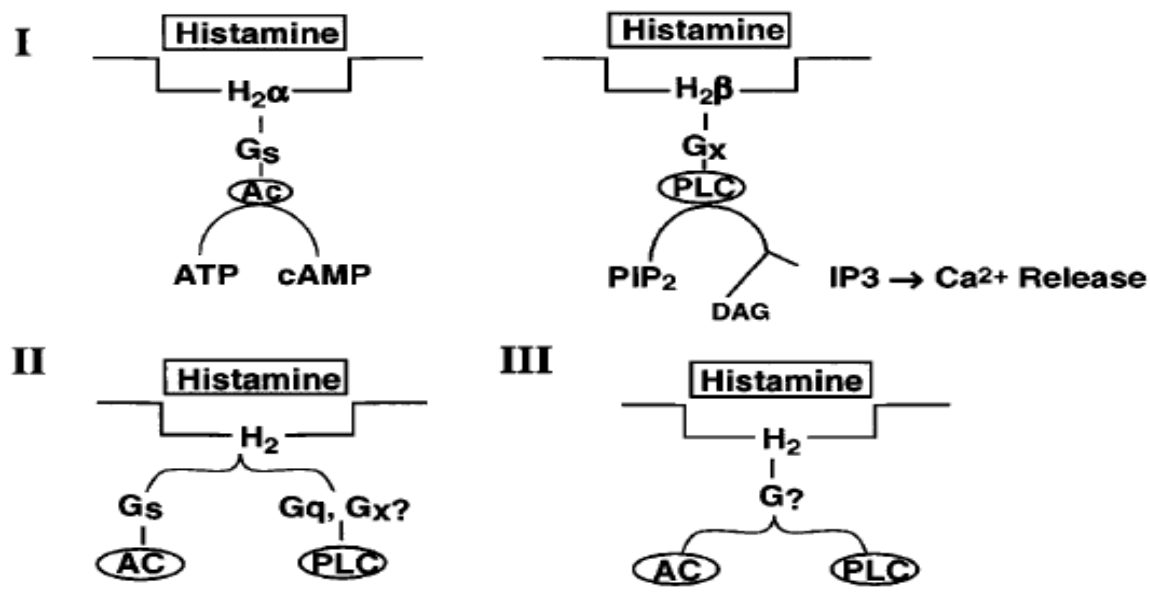

Figure 2. Potential models for H2 receptor-mediated coupling [Del Valle and Gantz, 1997]

Also, the activation of PLA2, the stimulation of mitogen-activated protein (MAP) kinase, phosphatidyl inositol 3-kinase (PI3K), and the $\beta$ and $\gamma$ subunits interact by N-type voltage gated calcium channels, to diminish function potential mediated influx of calcium and 
therefore decrease release of noradrenaline in human and guinea pig heart. H3 receptors action as presynaptic autoreceptors on histamine-containing neurons (Figure 3) (Bhowmik et al., 2012).

While H4R signals through Gi/o receptors, result in inhibition of cAMP production, mobilization of intracellular [Ca2+]i , and actin polymerization. In addition, H4R has been reported to activate mitogen-activated protein kinases and the JAK/STAT signaling pathway.

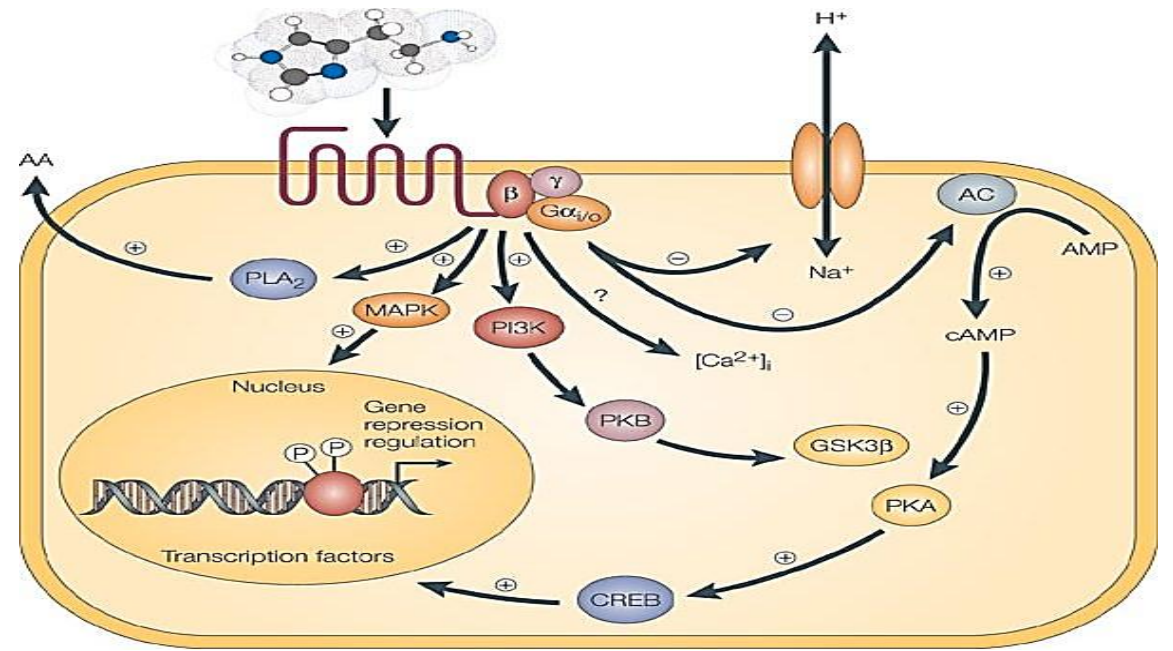

Figure 3. Proposed mechanism of H3 receptor activation [Leurs et al., 2005]

Furthermore PLC is activated by the dissociated G $\beta \gamma$ subunit after H4R activation. Importantly, histamine receptors can form dimers and oligomers, and this allow interaction among histamine receptors as well as other $\mathrm{G}$ protein-coupled receptors, therefore further develops the complexities of downstream signaling events in response to histamine stimulation (Figure 4) (Lim et al., 2005; Horr et al., 2006; Hanuskova and Plevkova, 2013). Also Histamine can action on cell surface receptors (H1, H2, H3 and H4 R), It may also bind to some intracellular receptors including cytochrome p450 and cytochrome c and highaffinity lipocalins isolated from the saliva of ticks (Hanuskova and Plevkova, 2013).

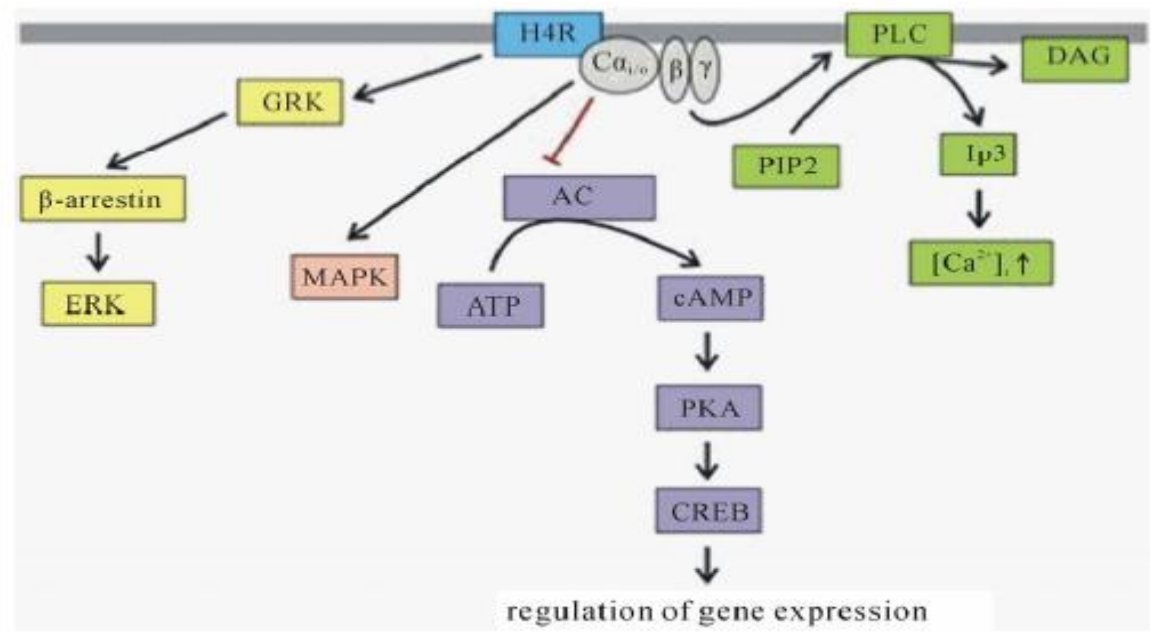

Figure 4. Signal transduction pathways activated by the H4R [Hanuskova and Plevkova, 2013] 


\section{Roles in the body}

Histamine leads to smooth muscle cell contraction, vasodilation, allergic response, increased vascular permeability, mucus secretion, tachycardia, alterations of blood pressure, arrhythmias, and nociceptive nerve fibers (Maintz and Novak, 2007), as well as, histamine has been identified to play different roles in neurotransmission, immunomodulation, hematopoiesis, wound curing, day-night rhythm, the regulation of histamine polyamine-induced cell proliferation and angiogenesis in tumor models and intestinal ischemia (Figure 5) (Maintz and Novak, 2007; Coruzzi et al., 2012; Yanai and Tashiro, 2007).

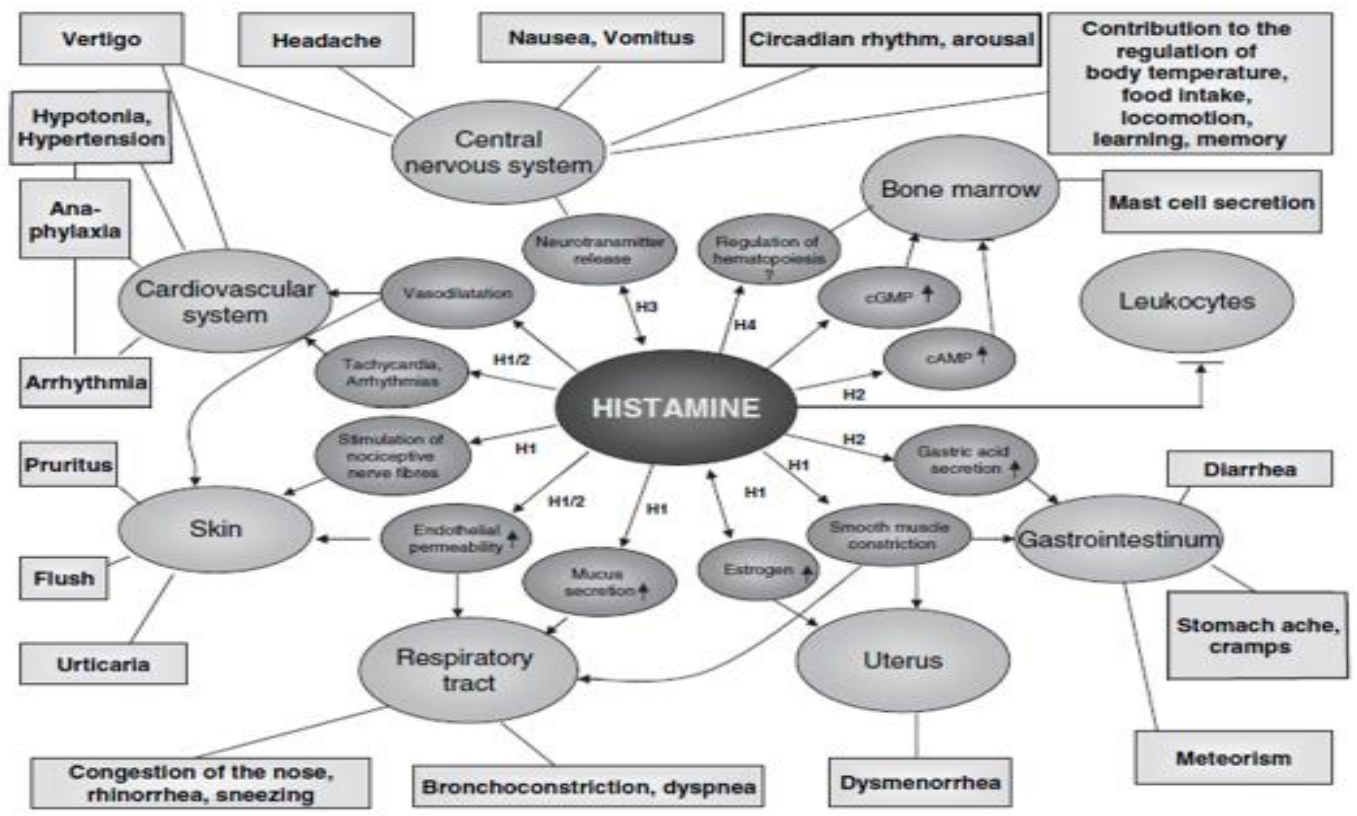

Figure 5. Summary of histamine-mediated symptoms [Maintz and Novak, 2007]

\section{Histamine in the GI tract: cellular sources, targets and receptors}

In the GI tract, histamine is synthesized and stored by different cell types, including mast cells, basophils, and enterochromaffin-like (ECL) cells; some reports indicate, G cells and enteric neurons, as well as myeloid and lymphoid cell types (dendritic cells, neutrophils, T cells etc.) do not store histamine, but display high HDC activity and are able of producing histamine to a varying degree, after activation with allergens, mitogens or cytokines (Coruzzi et al., 2012; Jutel et al., 2009).

In the GI tract, histamine plays a role in the large number of processes, such as acid secretion, mucosal defense, fluid transportation, neurotransmission, inflammation, immunity and carcinogenesis, targeting a variety of cell types (Coruzzi et al., 2012). These various biological functions performed by the four known histamine receptor subtypes, H1, H2, H3 and H4, that are expressed variously in during the gut. Vasodilation, rise in vascular permeability, contraction of smooth muscle, as well as intestinal fluid transport and visceral sensitivity is mediated by Histamine H1Rs (Coruzzi et al., 2012). H2Rs affect intestinal secretion, neurotransmission and immune responses, but they are main responsible for the physiological regulation of acid secretion from parietal cells. H3Rs mediate gastric mucosal defense, 
inhibition of enteric neurotransmission and feedback regulation of histamine release. According to studies performance in condition of in vivo and in vitro, suggested that the H4R can mediate a number of proinflammatory actions, such as, chemotaxis of neutrophil, mast cell and eosinophil and secretion of inflammatory cytokines, therefore, it is a novel target in inflammatory GI diseases (Figure 6) (Coruzzi et al., 2012; Coruzzi and Adami, 2008).

Increase in histamine concentrations or diminish degradation enzymes activities lead to various inflammatory and neoplastic diseases including Crohn disease, ulcerative colitis, allergic enteropathy, food allergy, and colorectal neoplasmas. So disequilibrium between product and inactivation of histamine result in histamine intolerance that has been suggested to play a role in the pathogenesis of these diseases (Maintz and Novak, 2007).

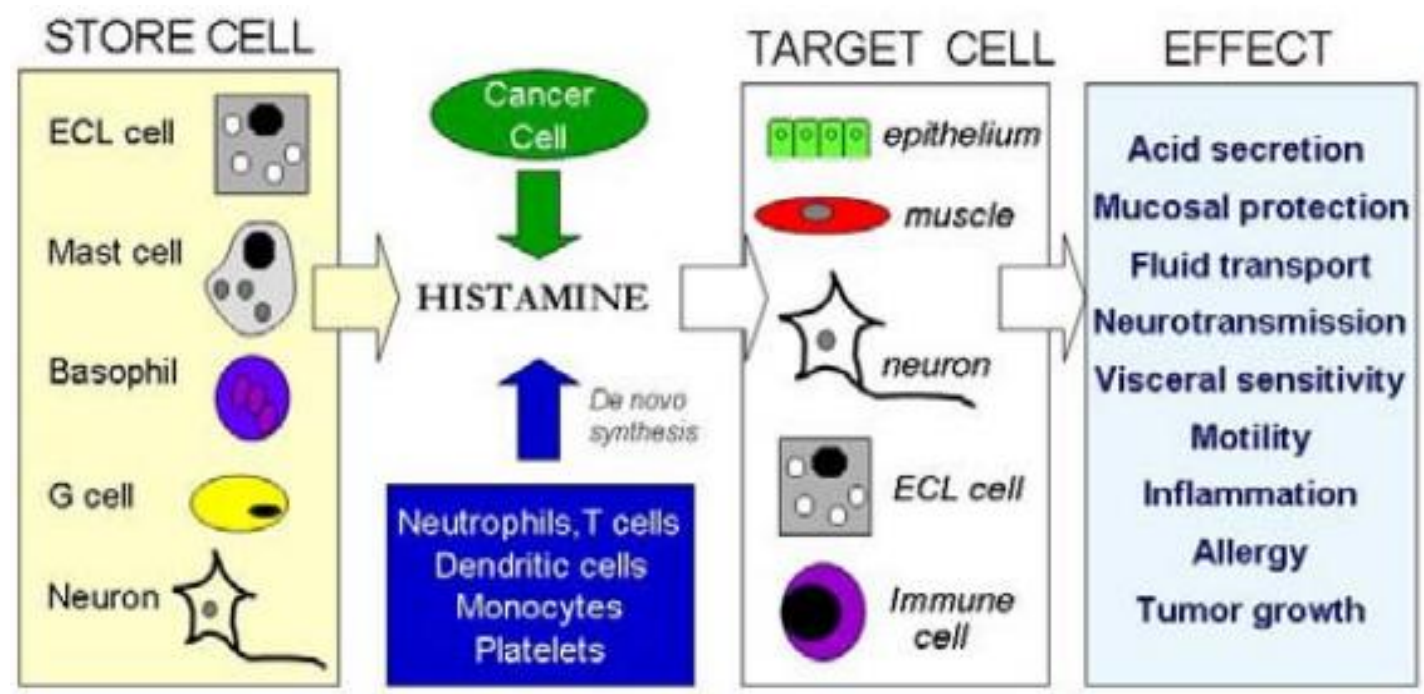

Figure 6. Important biological actions of histamine in the gastrointestinal tract, together with source of producing and target cells of histamine. Histamine can be produced from immune and cancer cells. Moreover, It can regulate tumor growth. ECL: enterochromaffin-like [Coruzzi et al., 2012]

\section{What is food allergy?}

Food allergy is a phenomenon in which immunological reactions are involved through antigenspecific immunological mechanisms following dietary exposure to relevant allergens or food proteins within food in susceptible individuals, and It is also reproduced through a doubleblind placebo-controlled food challenge (DBPCFC) (Kumar et al., 2012; Verhoeckx et al., 2015; Ho et al., 2014). Although, mortality due to food allergy is rare, but its anaphylactic reactions can lead to disorder in quality of life (Parrish et al., 2017). Estimates of its prevalence is up to $6 \%$ of young children and $3 \%-4 \%$ of adults. This defined is different from food intolerance, which describes a non-immunological adverse reaction to food, for example lactose intolerance (an enzyme deficiency) (Kumar et al., 2012; Verhoeckx et al., 2015). Symptom of Food allergy is complex and start between minutes to weeks after of take of food (Ho et al., 2014).

\section{Type of food allergy}

Food allergy based on their clinical features have three types: IgE mediated, non-IgE mediated and mixed (IgE/Non-IgE) (Ho et al., 2014), and according to the classical division of Gell and 
Coombs is 4 types of the immune response, and the percentage of spread their: type I-48\%, type II-6\%, type III-10\%, and type IV-18\%. (28). Food allergy also based on the World Allergy Organization is divided into two non-IgE-mediated and IgE-mediated (Anagnostou et al., 2015). IgE-Mediated Food Allergy that also is called type I hypersensitivity reactions is created as a result of make of IgE antibodies against food proteins or peptide. This particles can penetrate via skin, gut, or respiratory lining. Interaction between allergen and IgE antibodies attached to mast cells and basophils leading to release of histamine, tryptase, prostaglandins, leukotrienes, chemokines, etc. (Ho et al., 2014, Anagnostou et al., 2015). In this reaction, the clinical symptoms occur quickly as soon as uptake of food or within a short period of time (usually about $2 \mathrm{~h}$ ), and this IgE-mediated food allergies is called immediate (early). The presence of IgE antibodies in type I is the main criterion for the diagnosis of food allergy (Źukiewicz-Sobczak et al., 2013).

Allergic reaction-II, III or IV type are created by other immune response including T cells, IgG, IgM, IgA, and other immunologically competent cells, because of pathogenic mechanism, these reactions are defined as IgE-independent (Żukiewicz-Sobczak et al., 2013). Clinical symptoms of non-IgE mediated food allergy are subacute or chronic in nature and generally associated with isolated gastrointestinal and the skin symptoms (Ho et al., 2014, Anagnostou et al., 2015). This forms of food allergy are including enterocolitis, proctitis, proctocolitis, celiac disease, dermatitis herpetiformis, and food-induced pulmonary hemosiderosis (Ho et al., 2014).

The mixed type displays both clinical features IgE and non-IgE mediated food allergy because both eosinophilic and cellular components are involved in this type (Ho et al., 2014).

\section{Allergens}

Food allergens are defined as specific components of food or components within food (typically proteins; MW: $15 \mathrm{kDa}$ to $40 \mathrm{kDa}$ and glycoproteins; MW: $10 \mathrm{kDa}$ to $70 \mathrm{kDa}$, but sometimes also chemical haptens) that are recognized by allergen-specific immune cells and elicit abnormal response of the body, resulting in characteristic symptoms (Żukiewicz-Sobczak et al., 2013; Boyce et al., 2011). Allergens either raw or cooked or even after digestion in GI can have properties of antigenic (Boyce et al., 2011). The structure, and biochemical and physicochemical features of the allergen determine its allergenic strength. An allergen is bonded to paratopes of antibody through its epitopes, which are fragments of the antigen, the antigen epitopes that produce the strongest immune response in a certain species or individual, are named immunodominant determinants (Żukiewicz-Sobczak et al., 2013).

A list of more than 400 allergens and 200 isoallergens is developed by the allergen nomenclature subcommittee. Isoallergns are Allergens derived from a certain species that can be made up of molecules of a same structure (Żukiewicz-Sobczak et al., 2013).

\section{$\operatorname{Ig} \mathrm{E}$}

Immunoglobulin E (IgE) is one of the five immunoglobulins with the lowest concentration in the serum that has only been found in mammals and existed in tissues such as the lungs, skin and mucous membranes (Novak et al., 2001; Stone et al., 2010). People suffering from allergic symptoms have high levels from IgE antibody that they react with food allergens and other allergens. Because of the high impact of IgE in allergic patients, the total and specific IgE are good test to diagnose food allergy. Specific IgE level more than $0.35 \mathrm{kUA} / \mathrm{L}$ can be considered main regarding the prevalence of allergy due to any food, and may be used as a screening test (Novak et al., 2001). 


\section{Mechanism of food allergy induction}

Gut mucosa is one of the early sites for food allergic reactions, which have different types of cells such as regulatory $\mathrm{T}$ cells (Treg), Treg cells are divided into three major subtypes can be divided into three main subtypes, including FoxP3+ Treg cells (CD4+ T cells expressing Forkhead box P3 transcription factor), Th3 and Th1 (T helper cells). Th3 and Th1 cells secrete IL-10 and TGF-beta respectively, while Treg cells secrete both IL-10 and TGF- $\beta$ (Kumar et al., 2012).

Food allergens can penetrate to the mucosa. Then, antigen presenting cells especially dendritic cells (DCs) capture and internalize allergens. Ultimately allergens are get degraded to peptide fragments by proteosomal complex after attachment to ubiquitin, a 76-residue cytosol protein that is responsible for targeted protein degradation. The degraded peptide pieces are presented by major histocompatibility complex class-II (MHC-II) and identified via naïve CD4+ T cells or T helper cells. These cells have been classified into two wide classes Th1 and Th2, basically classified on the type of cytokines they produce. Th2 cells secrete cytokines IL-4 and IL-13. These cytokines lead to change a B cell's production of antibody to IgE, by a class switching biological phenomenon (Kumar et al., 2012).

The IgE immunoglobulin attaches to its receptor that it is found on surface of several cell types including, eosinophils, mast cells, basophils and epidermal Langerhans cells. This receptor is FceRI with different four subunits $\alpha, \beta, \gamma 1$ and $\gamma 2$. $\alpha$ and $\beta$ subunits of $\alpha$ and $\beta$ are involved in attachment of IgE, but $\gamma 1$ and $\gamma 2$ are involved in phosphorylation process (Novak et al., 2001). In secondary exposure of allergens, after crosslinking of allergens on IgE-FceR1 complex lead to activation of phosphorylation pathways. During of transport of signal, increase of DAG and IP3 molecules induced by PLC $\gamma$ and PI3K cause $\mathrm{Ca}^{+2}$ release from intracellular repository, which finally leads to mast cell degranulation (Figure 7) (Kumar et al., 2012).

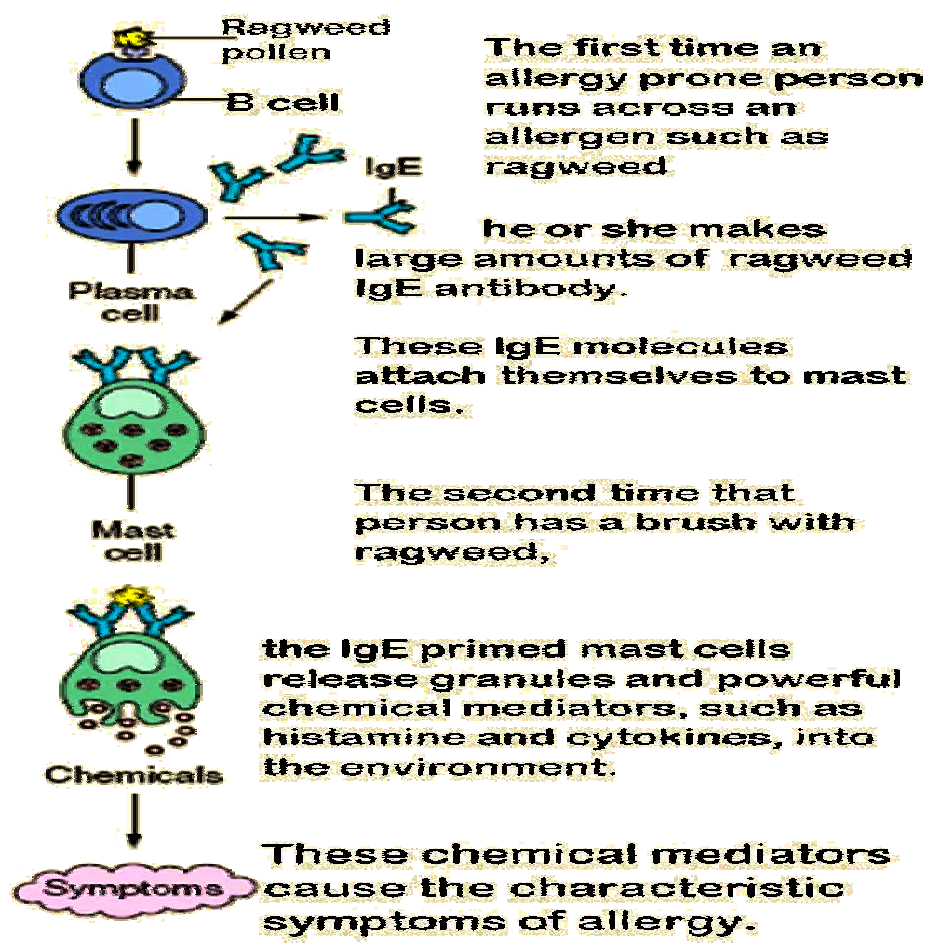

Figure 7. Mechanism of action food antigen 
Histamine, cytokines, leukotrienes, slow reacting substance of anaphylaxis (SRS-A), heparin, Prostaglandins, platelet-activation factor (PAF), proteolytic enzymes, eosinophil chemotactic factor of anaphylaxis and other mediators are secreted via degranulated mast cells or basophils (Kumar et al., 2012; Novak et al., 2001).

It is known that histamine is a main mediator released by basophils and mast cells after IgEmediated activation. released histamine effects on $\mathrm{H} 1$ and $\mathrm{H} 2$ receptors, and results in contraction of smooth muscles of the gastrointestinal and airway (GI) tract, enhances vasopermeability and vasodilation, elevated mucus production, cutaneous vasodilation, pruritus and gastric acid secretion. Therefore histamine in the gut cause abdominal pain, vomiting and diarrhea that these are symptoms of food allergy (De Benedetto et al., 2015; Kumar et al., 2012; Berin and Sampson, 2013).

\section{Conclusions}

There are four type of immune reaction (food allergy), therefore we have various diagnostic tests with different sensitivities and specificities. Hence it is rarely easy whether food intolerance is non-immunological or immunological etiology or is due to a mixture of the two mechanisms. Whenever the immune system chemicals (as: histamine, cytokines, etc) are released throughout the body may be cause a 'systemic' reaction (such as anaphylaxis), therefore the correct and timely diagnosis is very important. According to the findings of some studies, Measurement of N-methylhistamine (NMH) as the major metabolite of histamine may help to diagnose patients with food-allergen induced clinical symptoms. In addition, preventing the release of histamine, utilize of antihistamine, or rapid decomposition of histamine may be a treatment strategy for food allergy and other allergenic diseases. However, more effective forms of therapy and more specific diagnostic tests are need to more studies.

\section{References}

Anagnostou, K, Meyer, R, Fox, A, Shah, N. (2015). The rapidly changing world of food allergy in children. F1000Prime Rep., 7:35.

Backhaus, B, Raithel, M, Hahn, E. (2005). Nicht-immunologisch induzierte Histaminfreisetzung an vitalen menschlichen Darmschleimhautbiopsien durch Stimulation mit Polyaminen. Allergo J., 14:41.

Bakker, RA, Schoonus, SB, Smit, MJ, Timmerman, H, Leurs, R. (2001). Histamine H1-receptor activation of nuclear factor- $\kappa B$ : roles for $\mathrm{G} \beta \gamma$-and $\mathrm{G} \alpha \mathrm{q} / 11$-subunits in constitutive and agonist-mediated signaling. Mol. Pharmacol., 60(5):1133-1142.

Bäumer, W, Wendorff, S, Gutzmer, R, Werfel, T, Dijkstra, D, Chazot, P, Stark, H, Kietzmann, M. (2008). Histamine H4 receptors modulate dendritic cell migration through skinimmunomodulatory role of histamine. Allergy, 63(10):1387-1394.

Berin, MC, Sampson, HA. (2013). Food allergy: an enigmatic epidemic. Trend. Immunol., 34(8):390-397.

Bhowmik, M, Khanam, R, Vohora, D. (2012). Histamine H3 receptor antagonists in relation to epilepsy and neurodegeneration: a systemic consideration of recent progress and perspectives. Br. J. Pharmacol., 167(7):1398-1414. 
Boyce, JA, Assa'ad, A, Burks, AW, Jones, SM, Sampson, HA, Wood, RA, Plaut, M, Cooper, SF, Fenton, MJ, Arshad, SH, Bahna, SL, Beck, LA, Byrd-Bredbenner, C, Camargo, CA, Eichenfield, L, Furuta, GT, Hanifin, JM, Jones, C, Schwaninger, JM. (2011). Guidelines for the diagnosis and management of food allergy in the United States: summary of the NIAID-sponsored expert panel report. J. Am. Academy Dermatol., 64(1):175-192.

Coruzzi, G, Adami, M. (2008). Peripheral actions and therapeutic potential in periphery. The Third Histamine Receptor: Selective Ligands as Potential Therapeutic Agents in CNS Disorders. Boca Raton, CRC Press Taylor \& Francis, p. 167-209.

Coruzzi, G, Adami, M, Pozzoli, C. (2012). Role of histamine H4 receptors in the gastrointestinal tract. Front Biosci (Schol Ed), 4:226-239.

De Benedetto, A, Yoshida, T, Fridy, S, Park, JE, Kuo, IH, Beck, LA. (2015). Histamine and skin barrier: are histamine antagonists useful for the prevention or treatment of atopic dermatitis? J. Clin. Med., 4(4):741-755.

Del Valle, J, Gantz, I. (1997). Novel insights into histamine H2receptor biology. Am. J. Phys. Gastroint. Liver Physiol., 273(5):G987-G996.

Griffiths, C. E. M., \& Barker, R. D. R. (2004). Psoriasis. In: Rook-W. Wilkinsum Ebling. Text book of dermatology, Last ed. Blackwell Science.

Gutowska-Owsiak, D, Greenwald, L, Watson, C, Selvakumar, TA, Wang, X, Ogg, GS. (2014). The histamine-synthesizing enzyme histidine decarboxylase is upregulated by keratinocytes in atopic skin. Br. J. Dermatol., 171(4):771-778.

Gutzmer, R, Gschwandtner, M, Rossbach, K, Mommert, S, Werfel, T, Kietzmann, M, Baeumer, W. (2011). Pathogenetic and therapeutic implications of the histamine H4 receptor in inflammatory skin diseases and pruritus. Front Biosci (Schol Ed), 3:985-994.

Hanuskova, E, Plevkova, J. (2013). The role of histamine $\mathrm{H} 4$ receptors as a potential targets in allergic rhinitis and asthma. Open J. Mol. Integrat. Physiol., 3(01):6.

Ho, MHK, Wong, WHS, Chang, C. (2014). Clinical spectrum of food allergies: a comprehensive review. Clin. Rev. Allergy Immunol., 46(3):225-240.

Horr, B, Borck, H, Thurmond, R, Grösch, S, Diel, F. (2006). STAT1 phosphorylation and cleavage is regulated by the histamine $(\mathrm{H} 4)$ receptor in human atopic and non-atopic lymphocytes. Int. immunopharmacol., 6(10):1577-1585.

Jemima, EA, Prema, A, Thangam, EB. (2014). Functional characterization of histamine H4 receptor on human mast cells. Mol. Immunol., 62(1):19-28.

Jutel, M, Akdis, M, Akdis, C. (2009). Histamine, histamine receptors and their role in immune pathology. Clin. Experiment. Allergy, 39(12):1786-1800.

Kumar, S, Verma, AK, Das, M, Dwivedi, PD. (2012). Molecular mechanisms of IgE mediated food allergy. Int. immunopharmacol., 13(4):432-439. 
Leurs, R, Bakker, RA, Timmerman, H, de Esch, IJ. (2005). The histamine H3 receptor: from gene cloning to H3 receptor drugs. Nat. Rev. Drug Discov., 4(2):107-120.

Leurs, R, Vische, HF, Wijtman, M, de Esc, IJ. (2011). En route to new blockbuster antihistamines: surveying the offspring of the expanding histamine receptor family. Trend. Pharmacol. Sci., 32(4):250-257.

Lim, HD, van Rijn, RM, Ling, P, Bakker, RA, Thurmond, RL, Leurs, R. (2005). Evaluation of histamine H1-, H2-, and H3-receptor ligands at the human histamine H4 receptor: identification of 4-methylhistamine as the first potent and selective H4 receptor agonist. J. Pharmacol. Exper. Therapeut., 314(3):1310-1321.

Maintz, L, Novak, N. (2007). Histamine and histamine intolerance. Am. J. Clin. Nutrit., 85(5):1185-1196.

Novak, N, Kraft, S, Bieber, T. (2001). IgE receptors. Curr. Opin. Immunol., 13(6):721-726.

Parrish, C. P., Kim, E. H., \& Bird, J. A. (2018). Interventional Therapies for the Treatment of Food Allergy. Immunology and allergy clinics of North America, 38(1), 77-88.

Raithel, M, Küfner, M, Ulrich, P, Hahn, EG. (1999). The involvement of the histamine degradation pathway by diamine oxidase in manifest gastrointestinal allergies. Inflammat. Res., 48(13):75-76.

Schwelberger, HG. (2004). Histamine N-methyltransferase (HNMT) enzyme and gene. Histamine: biology and medical aspects. Budapest, Hungary: SpringMed Publishing, p. 53-9.

Schwelberger, HG. (2004). Diamine oxidase (DAO) enzyme and gene. Histamine: biology and medical aspects. Budapest, Hungary: SpringMed Publishing, p. 43-52.

Stone, KD, Prussin, C, Metcalfe, DD. (2010). IgE, mast cells, basophils, and eosinophils. J. Allergy Clin. Immunol., 125(2):S73-S80.

Verhoeckx, KCM, Vissers, YM, Baumert, JL, Faludi, R, Feys, M, Flanagan, S, HerouetGuicheney, C, Holzhauser, T, Shimojo, R, van der Bolt, N, Wichers, H, Kimber, I. (2015). Food processing and allergenicity. Food Chem. Toxicol., 80:223-240.

Yanai, K, Tashiro, M. (2007). The physiological and pathophysiological roles of neuronal histamine: an insight from human positron emission tomography studies. Pharmacol. Therapeut., 113(1):1-15.

Żukiewicz-Sobczak, WA, Wróblewska,P, Adamczuk, P, Causes, PK. (2013). symptoms and prevention of food allergy. Advances in Dermatology and Allergology, Postepy. Dermatol. Alergol., 30(2):113.

How to cite this article: Negar Dinarvand, Reza Azizi, Histamine and Food Allergy. International Journal of Advanced Biological and Biomedical Research, 2020, 8(2), 100-111. Link: http://www.ijabbr.com/article 36418.html 